Contents list available at IJRED website

Int. Journal of Renewable Energy Development (IJRED)

Journal homepage: www.ijred.com

\title{
Solar PV Lighting and Studying after Sunset: Analysis of Micro-benefits in Off-grid Rural Ghana
}

\author{
G.Y. Obeng* \\ Technology Consultancy Centre, College of Engineering, Kwame Nkrumah University of Science and Technology, Kumasi, GHANA
}

\section{Article history:}

Received July 15, 2012

Received in revised form December 20, 2012 Accepted January 20, 2013

Available online

\begin{abstract}
Solar PV light provides school children living in off-grid rural communities the opportunity to have clean and bright lighting to study after sunset. On the contrary, lighting provided from poor sources can pollute and adversely affect human eyes during reading and writing. Using indicator-based questionnaires in cross-sectional surveys, households with and without solar PV lighting were surveyed in off-grid rural communities in Ghana. The study investigated lighting and children's studies after sunset. The results indicated that whereas solar PV light of 5-20 watts dc lamps was sufficient for 5-6 children to study together, lighting from kerosene lantern could be sufficient for 1-3 children. All things being equal, the results showed that children who use solar PV light to study upto 2 hours after sunset are likely to improve on their examination results. The extent to which solar PV lighting significantly impacts on studying after sunset was established using some identified indicators. Knowledge of the results provides understanding of the relative constraints in lighting services faced by children in rural communities without access to quality lighting. Such micro-level data will help to enhance policy and planning efforts to increase access to clean and renewable energybased lighting devices to achieve efficient visual comfort in off-grid rural communities.
\end{abstract}

Keywords: Ghana, off-grid rural communities, solar PV lighting, studying after sunset

\section{Introduction}

Though the policy of Government of Ghana is to achieve universal access to electricity by 2020, grid access of $60.5 \%$ in 2009 (EUEI-PDF 2012; World Bank 2012) and over 70\% in 2012 (MoEn 2012) remains unevenly distributed and skewed in favour of the urban population. Rural access to the national grid is relatively low with several dispersed cummunities deprived. A deprivation in electricity as a basic service is one of the dimensions of rural poverty in Ghana (GSS 2007). Under the National Electrification Scheme (NES) of Ghana, rural communities that are located more than $20 \mathrm{~km}$ from the national grid may not be connected to gridelectricity in the next decade (Energy Commission 2005). The consequence is that nearly 70 percent of rural households depend on kerosene lanterns for lighting (GSS 2002; GSS 2005).
There is widespread agreement that access to electricity is essential for the provision of basic services aimed at enhancing quality of education, health, information acquisition, agriculture etc. As a key component of government's energy policy, solar PV systems are being deployed, particularly in the rural areas, to increase access to electricity for socioeconomic activities. Despite considerable deployment of solar PV in Ghana there are uncertainties with regard to quantifying the benefits for the rural poor. Evidencebased results on benefits are less discussed relative to costs and there are lessons and feedback that are still not explored for planning and policy review. Without a clear quantification of the benefits for off-grid rural communities, potential users may not accept solar PV as an appropriate alternative to grid electricity. In this regard, people living in off-grid rural communities may see solar PV systems as inferior alternative source of electricity.

\footnotetext{
* Corresponding author: Mobile phone: 00233-244-289743

Email : geo_yaw@yahoo.com
} 
Therefore, this study focuses on analysing the interaction between solar PV lighting and studying after sunset in rural communities where grid-electricity is not extended. The central question guiding the study is: How does access to solar PV lighting contribute to enhance children's education in off-grid rural Ghana? The objectives of the study are three fold: (1) to identify indicators that can be used to measure the interactions between solar PV lighting and studying after sunset; (2) to analyze the benefits of solar PV electrification for educational purpose at the rural household level; and (3) to make recommendations on sustainable use of solar PV lighting for educational purposes to enhance quality of life in off-grid rural communities.

\section{Methodology}

\subsection{Study Areas and Research Methods}

Cross-sectional survey was the main data collection method. The survey was conducted in sixteen rural communities located in six districts of the following five regions in Ghana: Northern, Upper East, Upper West, Volta and Greater Accra regions. Fig. 1 is the map of Ghana showing all the regions and electricity access in the year 2010 .

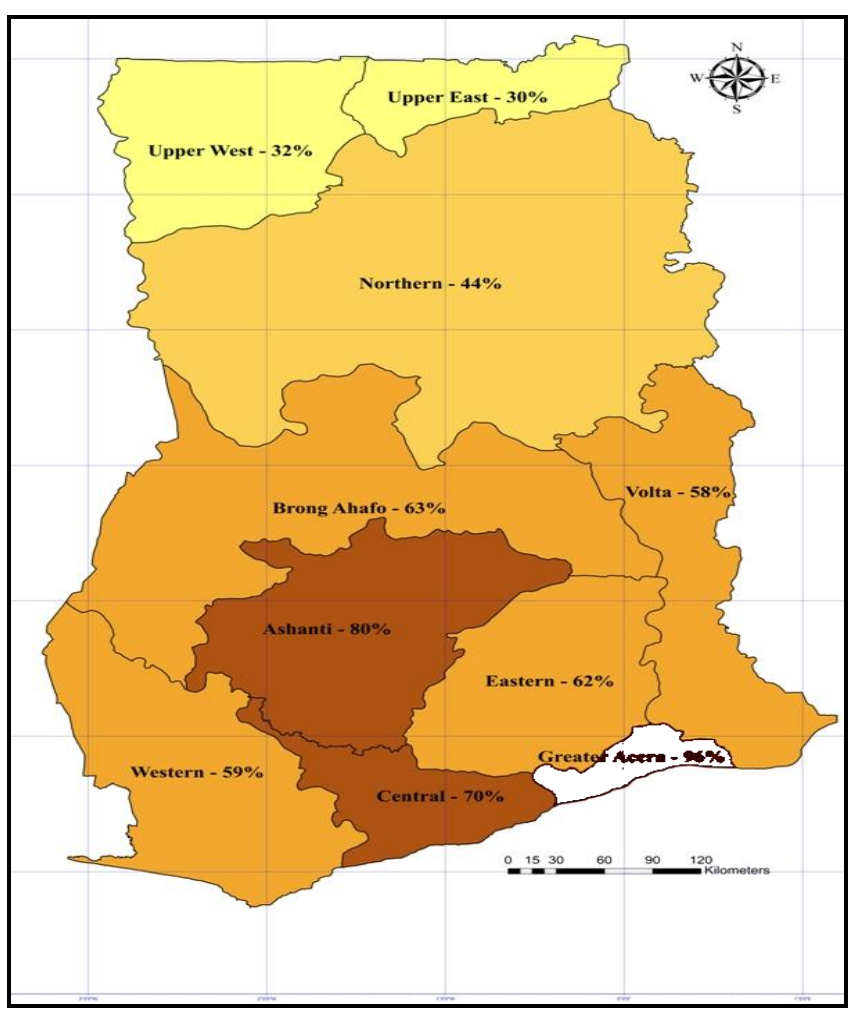

Fig. 1 Map of Ghana Showing the Regions and Electricity Access (in percent)

The study areas were off-grid rural communities with relatively high poverty incidence (GSS 2002). They include: Kpentang, Kpenbung, Kambatiak, Bamong,
Kintango, Chintilung, Tojing, Gbetmanpaak, Jimbali, Najong No.1 and Pagnatik in Bunkpurungu Yunyoo district and Kpalbe in East Gonja district (Northern region); Tengzuk in Talensi-Nabdam district (Upper East region); Wechiau in Wa-West district (Upper West region); Kpassa in Nkwanta district (Volta region); and Apollonia in Tema district (Greater Accra region). Pretesting of the questionnaires was carried out in the Nkoranza district of Brong-Ahafo region.

A total of 209 household heads were interviewed comprising 96 solar-electrified households and 113 non-electrified households. In each of the regions research assistants from the Kwame Nkrumah University of Science and Technology, Kumasi who speak the local language were engaged in the administration of the questionnaires. A list of (solarelectrified households) and incoming clients (nonelectrified households) were used to select the households in a systematic sampling.

From the lists of the beneficiaries of solar PV electrification projects in rural Ghana, solar home systems (50Wp and $100 \mathrm{Wp}$ ) that have been operational for over three years and had not been earmarked by the Ministry of Energy for relocation were selected. This criterion was based on the assumption that over a three-year period, PV systems and components (car battery, regulator and fluorescent lamp) would have gone through a cycle of operation and maintenance and end-users would have studied some impact lessons. Incoming clients were used as the comparison or control group because their lists were available for systematic sampling and they also appeared to be similar to the beneficiary group than random selected non-beneficiaries. School children related data focused on those in the ages of 8-14 years who were in the primary and junior high schools. The purpose of the questionnaire was to gather ex-post information, which indicates changes in the responses between households with and without solar PV.

\subsection{Underlying Assumptions and Data Analysis}

The underlying assumption that governed the interpretation of the study results was that in the absence of the solar PV lighting, the solar-electrified households would have solely depended on kerosene lanterns just like the non-electrified households. Kerosene lantern was used since it is the main lighting device for about $83 \%$ (year 2000) and 75\% (year 2003) of the population in rural Ghana (GSS 2007). The lighting sources taken into account in this study were selected according to their existence and use in the study areas. Exposure to solar PV lighting might have contributed to the difference or change in response between the households with and without solar PV.

In order to analyse the data, MS Excel 2007 and SPSS 16.0 for Windows was used. The data were cleaned by visually cross-checking the data base with the 
individual questionnaires to find out wrong entries; and by using box-plot to identify extreme values and outliers. Using descriptive statistics (cross-tabulation and statistical means) the relationship between households with and without solar PV and the indicators on education and information acquisition were analysed. The differences between the two groups in the responses to the indicators provide the basis for explaining how solar PV electrification has been responsible for the observed changes. Significant differences were observed using Pearson Chi-square and $\mathrm{p}$-values $(\mathrm{p}<0.05)$ were considered statistically significant.

\section{Results}

\subsection{Identified Indicators}

To measure the benefits that can be attributed to the type of lighting services available for reading and writing after sunset, four key indicators were selected. The indicators sought to measure the degree of change in benefits associated with the electrification status of the households. Table 1 outlines the indicators for measuring the benefits and assumptions.

\subsection{Lighting and children who could sit around lighting device}

Access to light in off-grid rural communities can permit children to extend their studies after sunset. Education offers the poor the opportunity to escape from poverty (Narayan et al. 2000). The results presented in Table 2 revealed that as household electrification status changes, a variation is observed between solar-electrified and non-electrified households. The results revealed that 1-3 children are likely to study with solar PV light in the evening, while in non-electrified households 2-3 children are likely to study with kerosene lantern in the evening. The group means show a significance level of the F-test as 0.000 $(\mathrm{p}<0.05)$, indicating a significant difference between the two groups of households. This study further examined whether solar PV light has any impact on the examination results of school children.

\subsection{Changes in examination results of children}

The purpose of the question was to examine the relationship between lighting and improvement in examination results between the school children (8-14 years) in the two groups of households. An improvement in the examination results of children leads to completion and graduation and better employment opportunities essential to improve quality of life. Table 3 shows the responses of the two groups of households. If the children in each household benefited from the same level of lighting, the pattern of responses were expected to be similar. However, from the results solar-electrified households had more children who improved on their examination results (73 percent) than non-electrified households (43 percent). A chisquare asymptotic significance (Sig. $=0.000$ ), indicates there may be a relationship between the type of lighting and improvement in examination results.

Additional information was obtained from the number of hours of study, which may be related to improvement in the examination results. A correlation of the indicators number of hours that children extend their study time with progressive change in children examination results gave a Pearson correlation of 0.178 , with significance (Sig. $=0.010$ ) at 0.01 significant level. This indicated some association between the two variables, though not very strong. By introducing the number of hours that children extend their study time as an intermediate variable the results are shown in Table4.

Table 1

Indicators for Measuring the Benefits

\begin{tabular}{|c|c|}
\hline Indicators & Assumptions \\
\hline 1. Number of children who could sit around lighting system. & 1. More children can be associated with quality lighting system. \\
\hline 2. Changes in examination results of children & 2. Improved examination results encourages education \\
\hline 3. Number of hours children could extend their studies & 3. Increased studies may result in better performance \\
\hline $\begin{array}{l}\text { 4. Number of households who reported of eye irritation of children due to } \\
\text { lighting }\end{array}$ & 4. Justification for access to clean and quality lighting \\
\hline
\end{tabular}

Table 2

Children who could sit around lighting device to study after sunset.

\begin{tabular}{|c|c|c|c|c|c|c|c|c|}
\hline \multicolumn{9}{|c|}{ 95\% Confidence Interval for Mean } \\
\hline HH Electrification Status & $\mathbf{N}$ & Mean & $\begin{array}{l}\text { Standard } \\
\text { Deviation }\end{array}$ & $\begin{array}{l}\text { Standard } \\
\text { Error }\end{array}$ & $\begin{array}{l}\text { Lower } \\
\text { Bound }\end{array}$ & $\begin{array}{l}\text { Upper } \\
\text { Bound }\end{array}$ & Min & Max. \\
\hline Solar-electrified & 96 & 5.39 & 2.460 & 0.251 & 4.89 & 5.88 & 0 & 8 \\
\hline Non-electrified & 113 & 2.40 & 1.567 & 0.147 & 2.11 & 2.69 & 0 & 8 \\
\hline Total & 209 & 3.77 & 2.512 & 0.174 & 3.43 & 4.11 & 0 & 8 \\
\hline \multicolumn{9}{|c|}{$F$ - test significance $=0.000$} \\
\hline
\end{tabular}


Citation: Obeng, G.Y. (2013) Solar PV Lighting and Studying after Sunset: Analysis of Micro-benefits in Off-grid Rural Ghana. Int. Journal of Renewable Energy Development, 2(1), 45-51

$\mathrm{P}$ a g e $\mid \mathbf{4 8}$

Table 3

Lighting and progressive change in children examination results

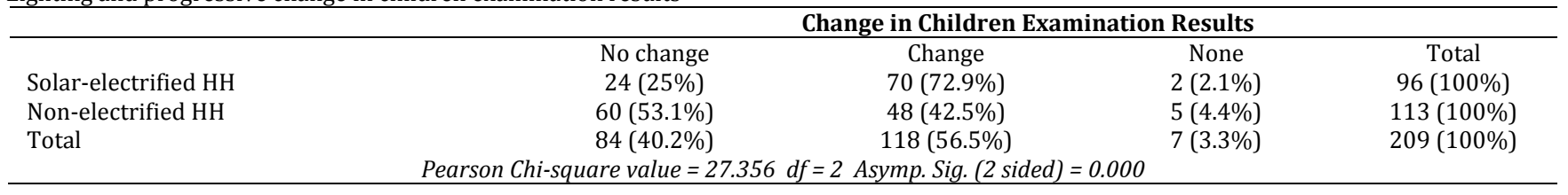

Table 4

Hours of extended study and change in exam results by household

\begin{tabular}{|c|c|c|c|c|}
\hline \multicolumn{5}{|c|}{ Change in Examination Results } \\
\hline $\begin{array}{l}\text { No. of hours in the evening children extend their } \\
\text { study time. }\end{array}$ & Response & $\begin{array}{l}\text { Solar-electrified } \\
\text { HH }\end{array}$ & $\begin{array}{l}\text { Non-electrified } \\
\text { HH }\end{array}$ & Total \\
\hline \multirow[t]{2}{*}{ One hour } & No change & $9(9.4 \%)$ & $35(31.0 \%)$ & $44(21 \%)$ \\
\hline & None & $5(5.2 \%)$ & $5(4.4 \%)$ & $10(5 \%)$ \\
\hline \multirow[t]{3}{*}{ Two hours } & No change & $2(2.1 \%)$ & $11(9.7 \%)$ & $13(6 \%)$ \\
\hline & Change & $24(25.0 \%)$ & $10(8.8 \%)$ & $34(16 \%)$ \\
\hline & None & $2(2.1 \%)$ & $3(2.7 \%)$ & $5(2 \%)$ \\
\hline \multirow[t]{3}{*}{ Three hours } & No change & $4(4.2 \%)$ & $5(4.4 \%)$ & $9(4 \%)$ \\
\hline & Change & $19(19.8 \%)$ & $9(8.1 \%)$ & $28(13 \%)$ \\
\hline & None & $1(1.0 \%)$ & $1(0.9 \%)$ & $2(1 \%)$ \\
\hline \multirow[t]{3}{*}{ Four hours } & No change & - & $1(0.9 \%)$ & $1(0.5 \%)$ \\
\hline & Change & $4(4.2 \%)$ & $4(3.5 \%)$ & $8(4 \%)$ \\
\hline & None & $1(1.0 \%)$ & - & $1(0.5 \%)$ \\
\hline \multirow[t]{3}{*}{ Five hours and above } & No change & - & $4(3.5 \%)$ & $4(2 \%)$ \\
\hline & Change & $10(10.4 \%)$ & $5(4.4 \%)$ & $15(8 \%)$ \\
\hline & None & $1(1.0 \%)$ & $1(0.9 \%)$ & $2(1 \%)$ \\
\hline \multicolumn{2}{|c|}{ Pearson Chi-Square $=5.8132$} & df $=2$ & \multicolumn{2}{|c|}{ Asymp. Sig. $=.055$} \\
\hline Pearson Chi-Squa & Pearson Chi-Square $=11.959$ & $\mathrm{df}=2$ & \multicolumn{2}{|c|}{ Asymp. Sig. $=.003$} \\
\hline Pearson Chi-Squa & Pearson Chi-Square $=1.696$ & $\mathrm{df}=2$ & \multicolumn{2}{|c|}{ Asymp. Sig. $=.428$} \\
\hline Pearson Chi-Squ & Pearson Chi-Square $=2.000$ & $\mathrm{df}=2$ & \multicolumn{2}{|c|}{ Asymp. Sig. $=.368$} \\
\hline Pearson Chi-Squa & Pearson Chi-Square $=5.632$ & $\mathrm{df}=2$ & \multicolumn{2}{|c|}{ Asymp. Sig. $=.060$} \\
\hline
\end{tabular}

\subsection{Household Lighting and Eye Irritation}

Household lighting after sunset enables families to extend their household activities after sunset. However, lighting provided from poor quality sources can affect the eyes. When asked whether children were affected by eye irritation as a result of the lighting sources used for studying after sunset, 23 percent of solar-electrified households reported that their children's eyes become red after studying for some time, while in the nonelectrified households, majority (69 percent) said their children's eyes were affected by the lantern they used for studying after sunset (Table 5). Overall, percent of households whose children were affected by eye irritation due to type of light was comparatively lower in solar-electrified than non-electrified households (Fig. 2). A chi-square asymptotic significance (Sig. = 0.000), indicates a significant difference in the responses between the solar-electrified and non-electrified households. The study further investigated whether there was a relationship between the extended hours of study and eye irritation.

\subsection{Household Lighting, Children's Extended Study Time and Eye Problem}

To determine if another factor accounted for the relationship between household lighting and eye irritation of children, a separate analysis was ran by controlling for the layer variable - number of hours of children's extended study. The results revealed that children who studied about 1-2 hours using kerosene lantern were those whose eyes appeared slightly red in the morning. Fig. 3 and Fig. 4 revealed the following: Firstly, children who studied about 1 hour in the evening: 45 (40 percent) of the non-electrified households $(\mathrm{N}=113)$ reported of eye problems affecting various numbers of children, while 13 (12 percent) said none. Five (5 percent) of the solar-electrified households $(\mathrm{N}=96)$ reported of eye effect, while 23 (24 percent) said none.

Secondly, for children who studied about 2 hours in the evening: 18 (16 percent) non-electrified households reported of eye problems, while six (5 percent) said none. Nine (9 percent) solar-electrified households reported of eye effect; while 19 (20 percent) said none. Low significance values for both Cramer's V Sig. $=0.000$ $(\mathrm{p}<0.05)$ and the Contingency coefficient Sig. $=0.002$ $(p<0.05)$, indicate that there is a relationship between lighting used for 1-2 hours of children's extended study and eye effect. Both values of the test statistics: Cramer's V $=0.593$ and 0.502; and Contingency coefficient $=0.510$ and 0.449 , indicate that the relation between the two variables is a fairly strong one. 
Table 5

Households who reported of eye irritation due to lighting

\begin{tabular}{|c|c|c|c|c|c|c|c|c|c|}
\hline & $\geq 5$ & 5 & 4 & 3 & 2 & 1 & Affected & $\begin{array}{c}\text { Not } \\
\text { Affected }\end{array}$ & Total \\
\hline $\begin{array}{l}\text { Solar- } \\
\text { electrified }\end{array}$ & $\begin{array}{c}1 \\
(1.0 \%)\end{array}$ & $\begin{array}{c}3 \\
(3.1 \%)\end{array}$ & - & $\begin{array}{c}1 \\
(1.0 \%)\end{array}$ & $\begin{array}{c}7 \\
(7.3 \%)\end{array}$ & $\begin{array}{c}10 \\
(10.4 \%)\end{array}$ & $\begin{array}{c}22 \\
(23 \%)\end{array}$ & $\begin{array}{c}74 \\
(77 \%)\end{array}$ & $\begin{array}{c}96 \\
(100 \%)\end{array}$ \\
\hline $\begin{array}{l}\text { Non- } \\
\text { electrified }\end{array}$ & $\begin{array}{c}2 \\
(1.8 \%)\end{array}$ & $\begin{array}{c}8 \\
(7.1 \%)\end{array}$ & $\begin{array}{c}6 \\
(5.3 \%)\end{array}$ & $\begin{array}{c}16 \\
(14.2 \%)\end{array}$ & $\begin{array}{c}18 \\
(15.9 \%)\end{array}$ & $\begin{array}{c}28 \\
(24.8 \%)\end{array}$ & $\begin{array}{c}78 \\
(69 \%)\end{array}$ & $\begin{array}{c}35 \\
(31 \%)\end{array}$ & $\begin{array}{c}113 \\
(100 \%)\end{array}$ \\
\hline Total & $\begin{array}{c}3 \\
(1.4) \\
\end{array}$ & $\begin{array}{c}11 \\
(5.3 \%)\end{array}$ & $\begin{array}{c}6 \\
(2.9 \%) \\
\end{array}$ & $\begin{array}{c}17 \\
(8.1 \%)\end{array}$ & $\begin{array}{c}25 \\
(12.0 \%) \\
\end{array}$ & $\begin{array}{c}38 \\
(18.2 \%) \\
\end{array}$ & $\begin{array}{c}100 \\
(48 \%) \\
\end{array}$ & $\begin{array}{c}109 \\
(52 \%) \\
\end{array}$ & $\begin{array}{c}209 \\
(100 \%)\end{array}$ \\
\hline
\end{tabular}

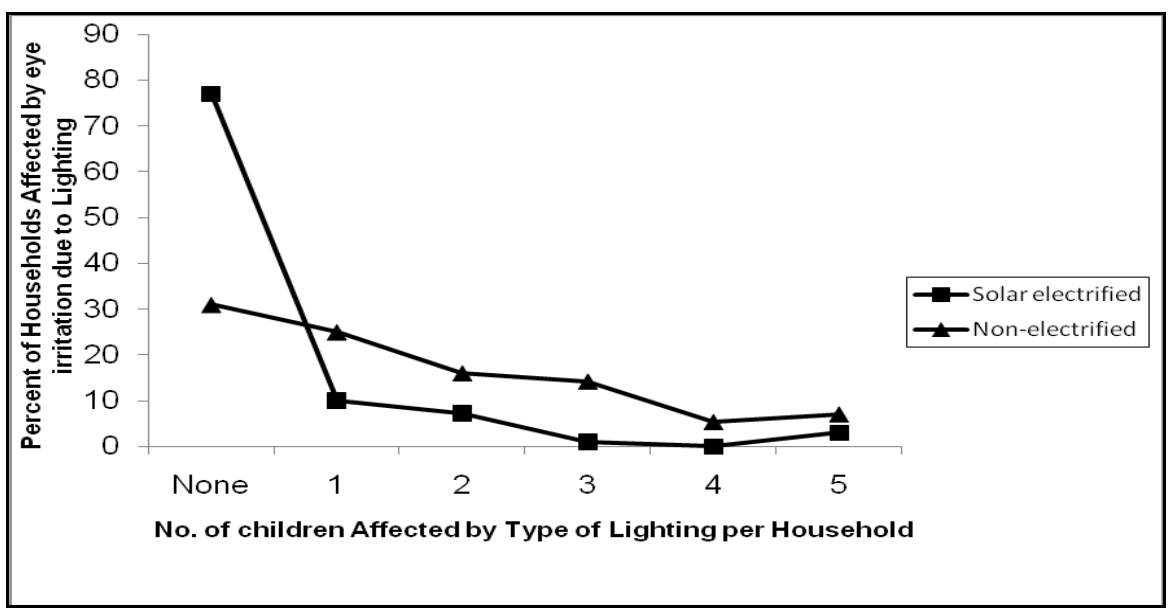

Fig. 2 Percent of households whose children were affected by type of lighting used

Children's Extended Study $=$ One Hour

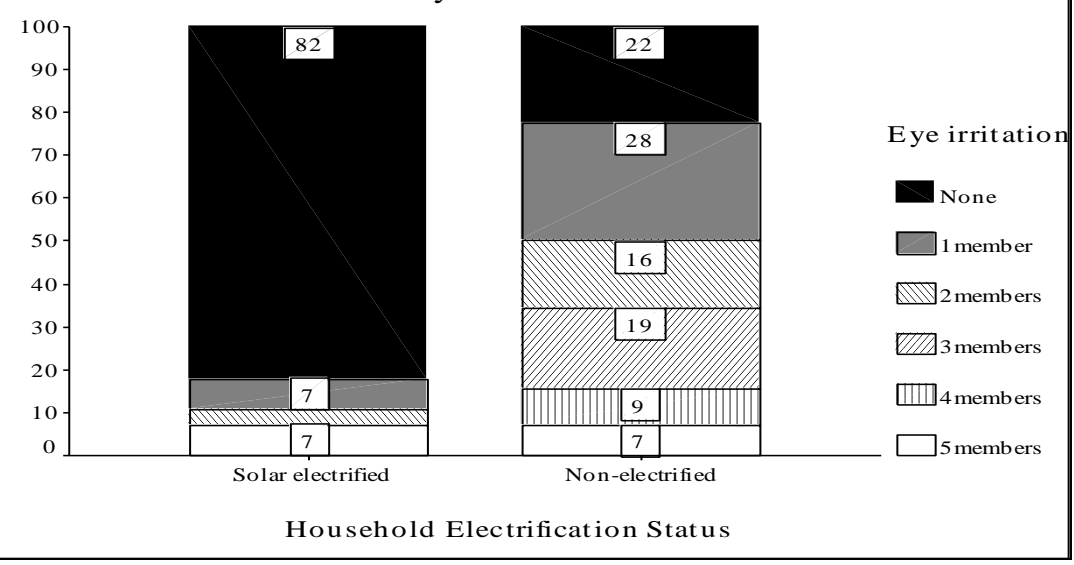

Fig. 3 Children extended study time of one hour and eye irritation

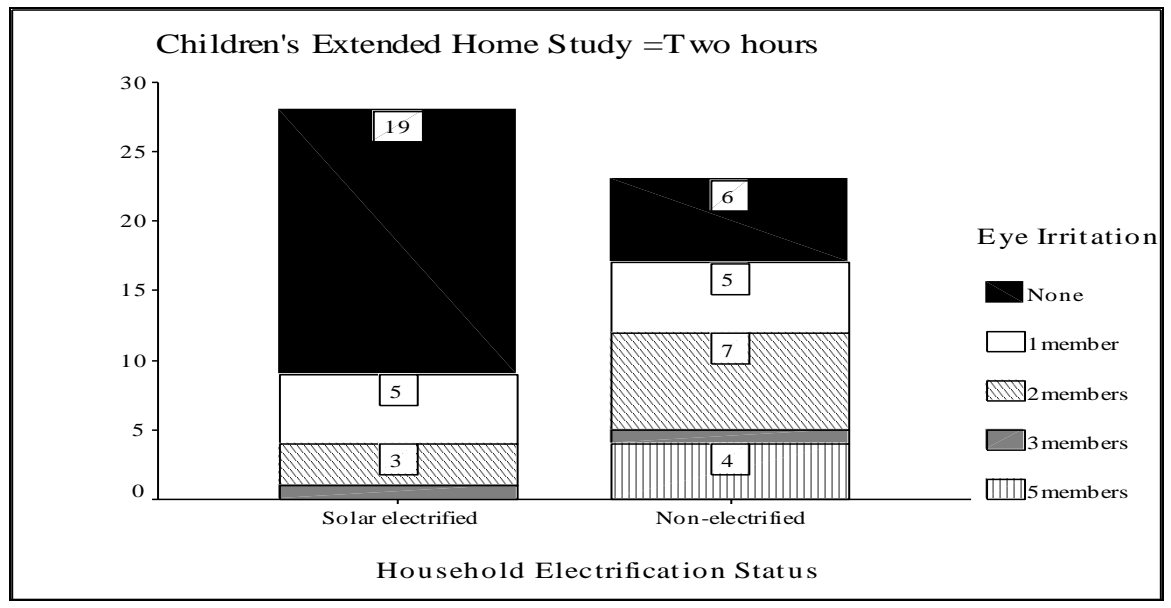

Fig. 4 Children extended study time of two hours and eye irritation 


\section{Discussion}

The importance attributed to children's education was deepened after the Millennium Development Goals (MDGs) were stated in year 2000. Key for development is the achievement of universal primary education Goal 2 (UNDP 2004; World Bank 2006). According to Zepeda (2006), this goal is within reach for most regions, with the exception of sub-Saharan Africa. The results on lighting and children's extended hours of study revealed that whereas a household solar PV light (typically 5-20 watts dc lamps) was sufficient for 5-6 children to study together, a kerosene lantern was sufficient for 1-3 children. In the surveyed households, there were about 5 children per household. The children usually used one lantern to study while the parents, usually the mothers, used the second lantern for household chores. Assuming that the solarelectrified households used one 7- 8 watts fluorescent light (without a reflector), then each child would receive about 259-296 lumens ${ }^{2}$ of light $\div 5$ children $=50-60$ lumens/child. Luminous efficiency of fluorescent lights without a reflector of 37 lumens per watt is assumed as indicated in Floor and Van der Plas (1998). In the case of the non-electrified households, where kerosene lanterns were used it would be 47.5 lumens $^{3}$ of light $\div 2$ children $=24$ lumens $/$ child. If 5 children use a lantern, then each child will receive 47.5 lumens $\div 5=10$ lumens per child.

Therefore, comparatively children using solar PV light have better quality lighting to study after sunset than children using kerosene lanterns. According to Van der Plas (1988), observations indicate that people who use kerosene for lighting accept much lower lighting levels than people who use electricity (Floor \& Van der Plas 1998). It is reported that kerosene lamps provide 10-50 times less light than an incandescent lamp, depending on the type of bulb (Barnes 2002). Solar PV light provides school children the opportunity to have quality light to improve their knowledge in the evening (Allderdice \& Rogers 2000; UNDP 2004). The ability to extend education after sunset is linked to the provision of high quality lighting (Wamukonya \& Davies 2001). Though the results corroborate the findings of the authors, it further provides quantitative data on the number of children that can conveniently study with a single solar PV light or a single kerosene lantern in a rural "off-grid" location. Knowledge of the quantitative data provides understanding of the relative energypoverty status and constraints in lighting services faced by children in households without high quality lighting. Such micro-level data will help to escalate policy efforts on rural electrification.

\footnotetext{
2 Luminous efficiency of fluorescent lights without a reflector of 37 lumens per watt is assumed (see Floor, W.M. and Van der Plas, R [(1998).

3 Based on the light output of kerosene wick lantern measured by Van der Plas (1988)
}

On examination results, though the results indicated some differences, the responses of the two groups of households did not reflect what was responsible for the improvement in examination results of the children. Therefore, number of extended hours of study was introduced as an intermediate variable. A separate analysis of the test for the relationship between extended hours of study and improvement in examination results indicated a significant value of $0.003(\mathrm{P}<0.05)$ for children who used solar light to study upto 2 hours. This finding suggests that the relationship observed in the cross-tabulation was real for children who studied with solar PV light upto 2hours. To examine the strength of the relationship, Phi, Cramer's V and Contingency Coefficient measures were all 0.003, indicating a statistically significant relationship.

Studies reporting of factors that associate positively with children's academic performance are common in the literature (Barnes 2002; Nsiah-Peprah \& KyiiliyangViiru 2005). Barnes study on rural electrification and development in the Philippines found that the educational level of the household head, employment status of children and housing characteristics affect children's reading and study at home (Barnes 2002). In another study on the factors affecting the standard of education in Junior Secondary Schools in the Upper East region of Ghana, it was found that small family size, parents' level of education, parents' occupational status, payment of school fees, parents concern for children's education and staff quality impact positively on children's academic performance (Nsiah-Peprah \& Kyiliyang-Viiru 2005). The findings of this study, therefore, contribute to the factors associating positively with the study time of children and academic performance, especially in rural communities without electricity. On the basis of the results, this study makes a contribution that all things being equal; children who use solar PV light to study upto 2 hours after sunset are likely to improve their examination results.

\section{Conclusions and recommendations}

The extent to which solar PV lighting is likely to benefit off-grid rural households was established using some identified indicators. It was established that solar PV lighting provides some benefits that enable children to extend their study time at home beyond daylight hours. The difference in the responses provided by households with and without solar PV light suggests an overall benefit of solar PV lighting to children after sunset. It was also established that relatively more children can sit together and study with solar PV light after sunset because of access to quality lighting in terms of more lumens as well as visual comfort. Children living in households with solar PV lighting were able to extend their studies with less effect on their eyes and this resulted in some changes in 
examination results that could be associated with access to quality lighting from electric source. On the contrary, knowledge of the research results provides understanding of the relative constraints in lighting services faced by children in rural communities without access to electric lighting sources that are clean and bright. Such micro-level data will help to enhance policy and planning efforts to increase access to solar PV lighting as an appropriate alternative to grid-electricity in off-grid rural communities.

\section{References}

Allderdice, A., \& Rogers, A.J. (2000) Renewable Energy for Micro Enterprise. Colorado: National Renewable Energy Laboratory (NREL) Publication.

Barnes, D.F. (2002) Rural Electrification and Development in the Philippines: Measuring the Social and Economic Benefits. UNDP/ESMAP Report. Washington: World Bank.

Energy Commission (2005) Off-grid Rural Electrification Programme OEP Phase 1. Renewable Energy Division Document, Accra, Ghana.

EUEI-PDF (2012) Monitoring Progress in the Africa-EU Energy Partnership. The European Union Energy Initiative-Partnership Dialogue Facility (EUEI-PDF) and Africa-EU Energy Partnership (AEEP) Publication, May 2012, Eschborn, Germany.

Floor, W.M., \& Van der Plas, R. (1998) Rural Lighting Services: A Comparison of Lamps for Domestic Lighting in Developing Countries. Energy Issues No. 12, The World Bank.
GSS (2002) Population and Housing Census. Summary Report of Final Results Statistical Service, Accra: Ghana Statistical Service (GSS).

GSS (2005) Population Data Analysis Report: Policy Implications of Population Trends (Vol.2), Accra: Ghana Statistical Service (GSS).

GSS (2007) Pattern and Trends of Poverty in Ghana 1991-2006, Accra: Ghana Statistical Service (GSS).

MoEn (2012) Ghana Set to Become Power House in West Africa. An Article of Ministry of Energy (MoEN), Rebublic of Ghana. Available online at [http://www.energymin.gov.gh/]

Narayan, D., Patel, R. and Schafft, K. (2000) Voices of the Poor: Can Anyone Hear Us? WB-0960. New York: Oxford University Press.

Nsiah-Peprah, Y., and Kyiiliyang-Viiru, L. (2005) Assessment of the Factors Affecting the Standard of Education in Junior Secondary Schools in the Kassena-Nankana District in the Upper East Region of Ghana, Journal of Science and Technology, 25(1), 43-57.

UNDP (2004) World Energy Assessment. Overview 2004 Update. Goldemberg, J. and Johansson, T.B (Eds.). Vienna: A UNDP Publication.

Van der Plas, R. (1988) Domestic Lighting. Policy, Planning and Research Working Papers, Industry and Energy Department, The World Bank WPS 68, Washington, D.C.

Wamukonya, N., and Davies, M. (2001) Socio-economic Impacts of Rural Electrification in Namibia: Comparisons between Grid, Solar and Non-electrified Households, Energy for Sustainable Development, 5(3), 5-13

World Bank (2006) World Development Report. Equity and Development. Washington D.C: World Bank.

World Bank (2012) Access to Electricity (\% of Population): Ghana. Available online [http://data.worldbank.org/indicator/EG.ELC.ACCS.ZS], (accessed July 26, 2012)

Zepeda, E. (2006) Inequality and MDG's Education Goal for Latin America, UNDP-International Poverty Centre (IPC), One Pager No. 23. 